\title{
Effects of figure-ground contrast and contour orientation on figural masking
}

\author{
Robert H. Pollack \\ INSTITUTE FOR JUVENILE RESEARCH
}

\begin{abstract}
Figural masking was investigated as a function of the amount of the contrast between concentric, successively-presented figures, and also as a function of the parallelism of the contours of the figures. It was found that masking occurred only when contrast was great and occurred to the greatest degree when contours of the inner and outer figures were parallel. Masking was inhibited by nonparallelism and by the presence of angles within the masked figure.
\end{abstract}

\section{Introduetion}

The early work of Werner (1935) on the visual masking of one briefly presented figure by a subsequent figure raised a number of problems concerning nontemporal stimulus variables. Working with a disk followed by a ring, Werner found that (1) whether the figures were black on a white background or vice versa made no difference; (2) a partial ring would obliterate the part of the disk it bordered; and (3) the disk did not have to be as large in diameter as the inner circumference of the ring, a finding confirmed by Kolers \& Rosner (1960). Werner also found that he could produce masking using square figures, but only at shorter interstimulus intervals and only if the inner square filled the space within the boundaries of the square ring.

Apparently the presence of intersecting contours tends to prevent figural disappearance in the masking situation while parallel contours tend to "attract" and absorb each other. This hypothesis is supported by Werner's finding that in cases where the masked figure was barely detected, the corners of the masked squares were perceived first, but the centers of masked disks appeared first. The case for attraction of parallel contours is further supported by Ogasawara's (1952) study of the concentric circles illusion, by George's (1962) report of the attraction and occasional fusion of parallel lines following prolonged fixation, and by Pollack's (1963b) demonstration of similar effects with fixation of concentric squares. For intersecting contours, on the other hand, Pollack (1964) has shown the opposite effect and has discussed a possible mechanism to account for these phenomena of attracting and repelling. Finally, the stronger the figure-ground contrast or the contours of the masking figure relative to the masked figure, the more likely it should be for masking to occur. Oyama (1961) demonstrated such a relationship in his study of the concentric circle illusion.

From these results, it can be expected that a figure would be masked by a subsequently presented sur- rounding figure even if the initial figure did not fill the entire surrounding area, provided that the contours of the inner and outer figures were parallel to each other. If, however, projections of their contours intersected, masking might not take place. Further, the presence of intersections or angles within each figure would tend to inhibit but not eliminate masking. Decreasing the contrast between the inner and outer figures would also be expected to inhibit masking. Subjects

Two female graduate students of the Northwestern University Evening Division served as trained, paid Ss in all conditions of the experiment.

\section{Apparatus}

The masking sequence was produced by using a three-channel electronic tachistoscope (Scientific Prototype Corporation, Model GA). Illumination as measured at the eyepiece by a MacBeth Illuminometer was $4.7 \mathrm{ft} \mathrm{c}$ for all channels.

Proeedure

The sequence of presentation was: (1) figure to be masked-a white, light gray, or mid-gray disk (diameter $21.6 \mathrm{~mm}$ ) or a hexagon (point-to-point diameter $21.6 \mathrm{~mm}$ ) was presented for $12 \mathrm{msec}$; (2) illuminated interstimulus interval-a field of the same illumination as that of the background for figures $(4.7 \mathrm{ft} \mathrm{c}$ ) was presented for a variable interval; and (3) masking figure - a white circular or hexagonal ring $(10 \mathrm{~mm}$ thick, inner diameter $25 \mathrm{~mm}$ ) centered on a $5 \times 7$ in black card was presented for $12 \mathrm{msec}$. The maximum angular extent of any figure at a viewing distance of $1100 \mathrm{~mm}$ was $2^{\mathrm{O}} 20^{\prime}$. Maximum separation between inner and outer figures was $50^{\prime}$ ". Viewing was binocular.

Four stimulus sequences were employed: (A) disk-interval-ring, (B) hexagon-interval-hexagonal ring, (C) disk-interval-hexagonal ring, (D) hexagon-interval-ring. Each sequence was repeated three times, once each for white, light gray, and mid-gray inner figures. In each sequence the method of limits was used to determine the intervals which would produce masking of the first, or inner, figure. The step intervals were $10 \mathrm{msec}$, ranging upward from $0 \mathrm{msec}$. There were 32 counterbalanced trials in each sequence given in two sessions of 16 trials each at least a week apart. Testing was always carried out between 3:30 and 5:00 PM.

In each sequence, Ss were shown instances in which the inner figure could be seen clearly and instances in which it did not appear. They were told to say "yes" when they saw the inner figure and "no" when they did not.

\section{Results and Discussion}

The greatest interval over which masking would occur was expected for sequence $\mathrm{A}$, which met the condition of parallel contours and no angles. Sequence $B$ was expected to be next with parallel separated contours and sequences $\mathrm{C}$ and $\mathrm{D}$ to come last with little or no masking. The fact that the disk had no angles within it offered the possibility of some masking in sequence D.

Only the data for the mid-gray inner figures were analyzed since no masking at all occurred with the other figures. These data were analyzed employing a simple 


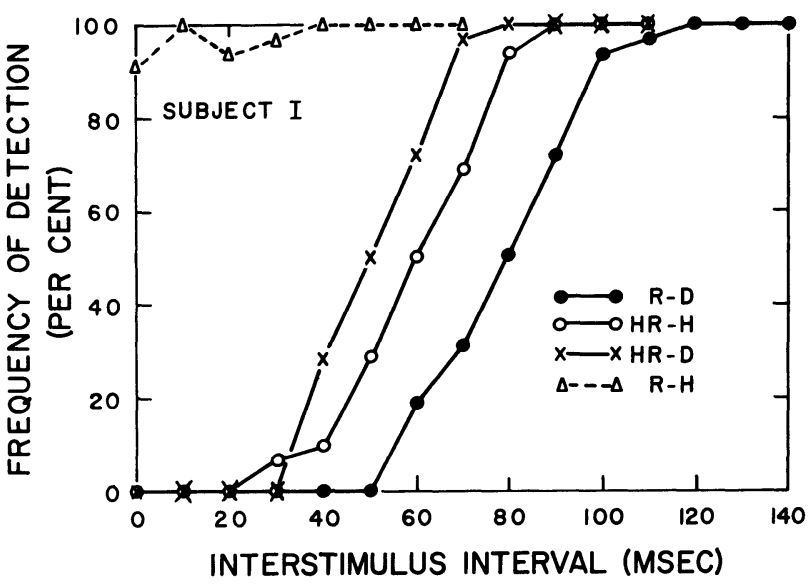

Fig. 1. Per cent detection of inner or masked figure as a function of interstimulus interval for S I.

randomized design one-way analysis of variance for each $\mathrm{S}$, with figure arrangement as the independent variable and the midpoints of the transition step interval for each trial as the dependent variable, (see Figs. 1 and 2). The hexagon-interval-ring sequence is not included because it produced almost no masking.

The analyses show comparable results with $\mathrm{F}=74.55$ $(\mathrm{df}=2,93 ; \mathrm{p}<.001)$ for $\mathrm{S} I$ and $F=83.43(\mathrm{df}=2,93$; $\mathrm{p}<.001$ ) for $\mathrm{S} \mathrm{II}$. All $\mathrm{F}^{\prime} \mathrm{s}$ between conditions for each $\mathrm{S}$ were significant beyond the .01 level of confidence. Since analysis of the raw data showed no consistent starting position effect, ascending and descending trials were combined.

The data for each $\mathrm{S}$ were plotted as per cent detection at each interstimulus interval (see Figs. 1 and 2). It can be seen that the Ss showed similar patterns of response, with maximum masking occurring in the angle-free disk-ring sequence, somewhat less in the angular but parallel hexagon-hexagonal ring sequence, even less in the disk-hexagonal ring combination and virtually none for the hexagon-ring combination.

Two conclusions seemed warranted. First, given the angular separation between inner and outer figures in this experiment, a large difference in figure-ground contrast in favor of the masking figure is necessary to produce masking. Second, contour orientation is an important factor in masking. Lack of parallelism of inner and outer figure contours inhibits masking, as does the presence of angles within the figure to be masked.

It appears, therefore, that the figural masking phenomenon may be in the same class as fixation effects

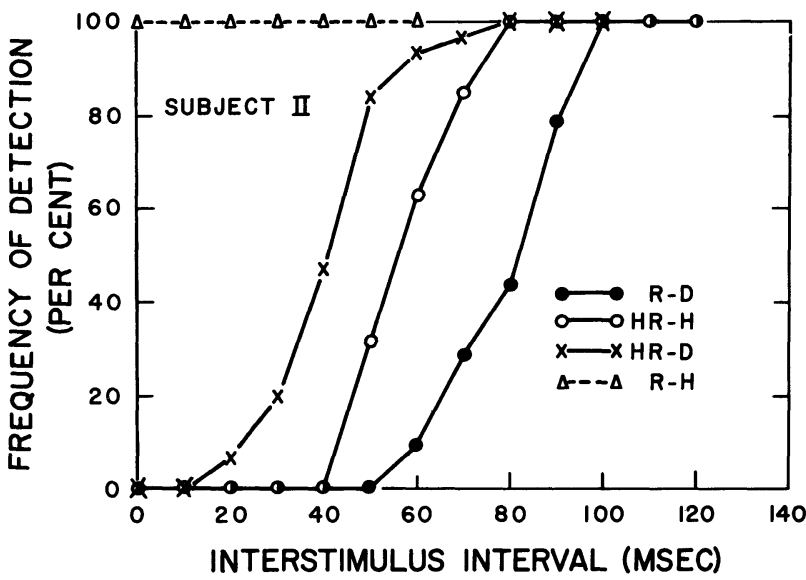

Fig. 2. Per cent detection of inner or masked figure as a function of interstimulus interval for S II.

(Pollack, 1964) and certain geometrical illusions (Oyama, 1961). That is, the magnitudes of the phenomena depend upon figure-ground contrast of the inducing or inspecting figures (here, the masking figure) and their contour orientations with respect to the test figures (here, the masked figure). If such is the case, a planned developmental study should yield data similar to that found with the other phenomena (Piaget et al, 1942; Pollack, 1963a), i.e., its magnitude should decline with age.

\section{References}

GEORGE, F. H. Acuity and the statistical theory of figural aftereffects. J. exp. Psychol., 1962, 63, 423-425.

KOLERS, P. A., \& ROSNER, B. S. On visual masking (metacontrast): Dichoptic observation. Amer. J. Psychol., 1960, 73, 2-21.

OGASAWARA, J. Displacement-effect of concentric circles. Jap. J. Psychol., 1952, 22, 16-25.

OYAMA, T. The illusion of concentric circles as a function of hue and brightness. Hokkaido Rep. Psychol., 1961, 6, No. 3 .

PIAGET, J., \& LAMBERCIER, M. Recherches sur le développement des perceptions: V. Essai sur un effet d' "Einstellung" survenant au cours de perceptions visuelles successives (effetU snadze). Arch. Psychol., Genéve, 1944, 30, 139-196.

POLLACK, R. H. Contour detectability thresholds as a function of chronological age. Percept. mot. Skills, 1963a, 17, 411-417.

POLLACK, R. H. Effects of temporal order of stimulus presentation on the direction of figural aftereffects. Percept. mot. Skills, 1963b, $17,875-880$.

POLLACK, R. H. The effects of fixation upon the apparent magnitude of bounded horizontal extent. Amer. J. Psychol., 1964, 77, 187-192. WERNER, H. Studies on contour: I. Qualitative analysis. Amer. J. Psychol., 1935, 47, 40-64. 